\title{
A ROUTE EFFICIENCY ANALYSIS BASED ON DATA ENVELOPMENT ANALYSIS: AN APPLICATION TO AGRICULTURE
}

\author{
Bisera Andrić Gušavac \\ University of Belgrade Faculty of Organizational Sciences \\ bisera@fon.bg.ac.rs \\ Gordana Savić \\ University of Belgrade Faculty of Organizational Sciences \\ gordana.savic@fon.bg.ac.rs \\ Milan Martić \\ University of Belgrade Faculty of Organizational Sciences \\ milan.martic@fon.bg.ac.rs
}

\begin{abstract}
This study employs data envelopment analysis (DEA) approach to evaluate the performance of agricultural aircraft routes. In the context of agricultural aircraft usage, not enough attention has been paid to the efficiency study of the routes in agricultural operations. Aircraft are used in agriculture to perform various treatments on agricultural land. Presumptions in this study are that a land is divided into parcels and one type of treatment must be performed on these parcels. Also, the considered operation is performed by the agricultural aircraft and the size of the analyzed land implies that all parcels cannot be treated in one route, so there are multiple routes which have to be completed. Here, we propose application of output oriented CCR DEA model on one set of routes in order to determine relatively efficient routes. Proposed inputs for the application of the DEA method are: tank capacity of an aircraft and total cost of parcel treatment in one route. Proposed outputs are: total treated land area (total area of all parcels in route) in one route and percentage share of effective flight in the total distance traveled in one route. In this way relatively efficient routes can be selected, and some further analysis of relatively inefficient routes can be made in order to see what changes can be done in inputs and / or outputs of these inefficient routes to improve their performance.
\end{abstract}

Keywords: Data envelopment analysis, Route efficiency, Agriculture

JEL classification: Q15, C67, 018

\section{INTRODUCTION}

When measuring the efficiency of systems with more diverse products (outputs) produced with more diverse materials (inputs), it is impossible to draw a conclusion regarding the level of success, i.e. efficiency, based on only a few (partial) indicators. Farrell (1957) defines a measure of technical efficiency (Farrell's measure) that allows the inclusion of multiple inputs (or multiple outputs) in an analysis. However, until the development of DEA (Data Envelopment Analysis) method, it was not possible to include multiple inputs (or multiple outputs) in the analysis at the same time as a methodology for evaluating efficiency.

Authors Charnes, Cooper, and Rhodes (1978) defined a basic model of data envelope analysis, which was primarily used to measure the efficiency of schools and hospitals (nonprofit sector). Later, the DEA method began to be used to measure efficiency in all areas 
where more inputs were used for production, and more diverse outputs were obtained as output.

The efficiency measure obtained for decision making units (DMU) is relative, because the efficiency of each unit is measured in relation to the others (all decision units in the observed set) and thus the value of the efficiency index depends on the number of inputs and its structure, and from the number of outputs and the structure of outputs, and of course from the number of decision-making units themselves. From the early 1990s, the DEA method, along with other techniques, began to be used in public transport research to compare outcomes (Singh et al., 2018). The efficiency of routes in public transport is evaluated in the large number of published papers, for example, the authors in the paper (Singh et al., 2018) use the DEA method to assess performance as the efficiency of bus routes. In this way, the authors determined which routes are efficient and which are inefficient and how inefficient ones can be transformed into efficient routes in accordance with the places of social priority.

Successful operational policy and planning of individual routes depends on a thorough understanding of route performance and economic characteristics. A great number of airline routes performance studies have considered companies as DMUs rather than individual routes; therefore, these studies may lack insight into the operation problems of each route. Only few studies treat each individual route as a DMU, like authors in (Chiou and Chen, 2006).

\section{ROUTE EFFICIENCY ANALYSIS USING DEA METHOD}

The subject of this research is the agricultural land treatment, i.e. selection of efficient routes (from the set of existing routes) in the treatment of agricultural land. The problem that is analyzed consists of performing one type of operation on a parceled agricultural land using agricultural aviation. The characteristics of the problem are: the land is divided into parcels; the surface of the whole land cannot be processed by a single plane over flight; a nonhomogeneous fleet of aircraft is used; processing of several parcels can be done with one over flight (depending on the capacity of the aircraft).

The application of solving methods (exact or heuristics) are not the subject of this paper, but application of these method(s) result in processing plans - that is, a set of routes the agricultural aircraft will take and process all the parcels on one agricultural land (Andric Gušavac et al., 2019). When a processing plan (a set of routes) is determined, DEA method can be applied to determine relatively efficient routes within one processing plan.

For successful application of DEA method it is necessary to follow the DEA procedure steps. The first phase in this procedure is selection of the DMU, according to Martic (1999), followed by selection of input and output criteria, solving the DEA model and analysis and results interpretation. In COOPER framework defined by authors Emrouznejad and Witte (2010), implementation of DEA method is divided into six phases (Savić, 2012), where the first two phases represent preparation for efficiency assessment, and relate to defining the objectives of the analysis and understanding the way decisions are made. Only after the preparation of data, the selection of an adequate model for efficiency assessment is made, and within this phase, all inputs and all outputs are defined. After applying the model over real data, it is necessary to prepare reports that will understandably help decision makers to improve their business.

Selection of relatively efficient routes using DEA within a single plan leads to implementation of the efficient routes first in practice. It is also possible to analyze relatively inefficient routes and notice what can change in their inputs and / or outputs so the inefficient routes become relatively efficient. Regarding the previously stated, it is very important to choose the appropriate variables. The appropriate selection of input and output variables can provide excellent problem insight regarding the relatively inefficient routes. Using the part of 
the solution called projection it is possible to single out inputs and/or outputs which can be changed in order to make an inefficient route efficient.

\subsection{Selection of input and output criteria}

Most published papers in this area analyze routes in public urban transport, while routes in air transport are covered in only two papers (Shao and Sun, 2016; Chiou and Chen, 2006). The input and output variables that are chosen in these papers are presented in Table 1.

Regarding the input factors in public urban transport, the route length is most often used (Singh et al., 2018; Güner et al., 2016; Deng and Yan, 2019; Lin et al., 2010), as well as fuel costs (Melo et al., 2018; Güner et al., 2016; Adhikari et al., 2018; Zhu et al., 2016; Yu and Chen, 2011; Chiou and Chen, 2006).

Table 1: Selected input and output variables for air transport

\begin{tabular}{|c|c|c|}
\hline $\begin{array}{l}\text { Shao and Sun, } \\
2016\end{array}$ & $\begin{array}{l}\text { Input of allocation stage: } \\
\text { Number of flights } \\
\text { Interphase measures: } \\
\text { Available seats } \\
\text { Available tonnage } \\
\end{array}$ & $\begin{array}{l}\text { Output of passenger transport function: } \\
\text { Passenger throughput } \\
\text { Output of freight transport function: } \\
\text { Cargo and mail throughput }\end{array}$ \\
\hline \begin{tabular}{l|} 
Chiou and \\
Chen, 2006
\end{tabular} & $\begin{array}{l}\text { Fuel costs } \\
\text { Staff costs } \\
\text { Aircraft cost (maintenance costs, } \\
\text { depreciation costs, interest) }\end{array}$ & $\begin{array}{l}\text { Cost efficiency: } \\
\text { Number of flights } \\
\text { Number of miles traveled per seat on the aircraft } \\
\text { Service efficiency: } \\
\text { Number of miles traveled per passenger } \\
\text { Number of passengers per boarding }\end{array}$ \\
\hline
\end{tabular}

Based on the selected input and output variables in the published papers and based on the specifics of the analyzed problem in this paper, proposed inputs for the application of the DEA method in agricultural land treatment are aircraft capacity and total cost of treatment of plots in the route. The capacity of the aircraft represents the total available fuel tank capacity of one aircraft and determines the total distance that the aircraft can fly. The total cost of treating parcels in one route represents the total cost of aircraft flying from / to the airport, the cost of flying between all parcels in the route, as well as the cost of treatment of each parcel in the route. Proposed outputs are total treated area of all parcels in the route and percentage share of effective flight in the total distance traveled. The total treated area of all parcels in one route represents the sum of the surface area of each parcel in one route. During the treatment of the parcels in one route, the aircraft must fly from / to the airport as well as fly the distance between each parcel in the route. It is important to note that only part of the flight (from the total flight in one route) related to parcel treatment in one route is an effective flight. In accordance with the above, the percentage share of effective flight in the total distance traveled is proposed as output variable.

Research that is planned consists of solving the examples for instances of the maximum dimensions: 100 plots and 21 aircraft. The solution will consist of the processing plan that will include routes that cover (treat) all plots in the example.

\section{CONCLUSION}

A part of the research that comprise of route efficiency analysis based on data envelopment analysis and applied to agriculture is presented in this paper. When it comes to practical benefits of this research, it is important to highlight that, based on efficient routes selected using DEA method, can be first implemented in practice. After the analysis of relatively inefficient routes, some changes in their inputs and / or outputs can be done and the inefficient 
routes can become efficient. Research in progress that is presented in this paper consists of selection of DMUs and selection of input and output variables. Future work will consist of selection of the DEA model which will be applied to solve the problem and the software that will be used is DEA-Solver-LV 8.0 (DEA Solver LV 8.0, 2019). The proposed approach will be tested on examples of different dimensions. One important analysis that will be conducted is projection which is important for relatively inefficient routes and based on the indicators and their values given in this analysis it can be perceived which inputs and / or outputs can be increased / decreased and by how much for each inefficient route so that the route becomes relatively effective. DEA method can help to explore the influence of different parameters to the efficiency of routes.

\section{REFERENCES}

Adhikari A., Basu S., Biswas I., Banerjee A., Sengupta P.P. (2018),"A route efficiency analysis using Shannon entropy-based modified DEA method and route characteristics investigation for urban bus transport in India", INFOR, Vol. 56 No. 3, pp. 332-359.

Charnes, A., Cooper, W., Lewin, A.Y. and Seiford, L.M. (1997), "Data envelopment analysis theory, methodology and applications", Journal of the Operational Research society, Vol. 48 No. 3, pp.332-333.

Chiou, Y.C. and Chen, Y.H. (2006), "Route-based performance evaluation of Taiwanese domestic airlines using data envelopment analysis", Transportation Research Part E: Logistics and Transportation Review, Vol. 42 No. 2, pp.116-127.

Deng Y., Yan Y. (2019), "Evaluating Route and Frequency Design of Bus Lines Based on Data Envelopment Analysis with Network Epsilon-Based Measures", Journal of Advanced Transportation.

Farrell, M.J.(1957), "The measurement of productive efficiency", Journal of the Royal Statistical Society: Series A (General), Vol. 120 No. 3, pp.253-281.

Güner S., Coşkun E. (2016), "Determining the best performing benchmarks for transit routes with a multi-objective model: the implementation and a critique of the two-model approach", Public Transport, Vol. 8 No.2, pp. 205-224.

Gusavac, B.A., Stanojevic, M. and Cangalovic, M. (2019), "Optimal treatment of agricultural land-special multi-depot vehicle routing problem", Agricultural Economics, Vol. 65 No. 12, pp.569-578.

Lin E.T.J., Lan L.W., Hsu C.S.T. (2010), "Assessing the on-road route efficiency for an airexpress courier", Journal of Advanced Transportation, Vol. 44 No. 4, pp. 256-266.

Martić, M., (1999). Analiza obavijenih podataka sa primenama, Doctoral dissertation. Faculty of Organizational Sciences, Belgrade, Serbia.

Melo I.C., Junior P.N.A., Perico A.E., Guzman M.G.S., Rebelatto D.A.N. (2018), "Benchmarking freight transportation corridors and routes with data envelopment analysis (DEA)", Benchmarking, Vol. 25 No. 2, pp. 713-742.

Savić G., (2012). Komparativna analiza efikasnosti u finansijskom sektoru, Doctoral dissertation. Faculty of Organizational Sciences, Belgrade, Serbia.

Shao Y., Sun C. (2016), "Performance evaluation of China's air routes based on network data envelopment analysis approach", Journal of Air Transport Management, Vol. 55, pp. 67-75.

Singh, P., Singh, A.K., Singh, P., Kumari, S. and Sangaiah, A.K. (2019), "Multimodal data modeling for efficiency assessment of social priority based urban bus route transportation system using GIS and data envelopment analysis", Multimedia Tools and Applications, Vol. 78 No. 17, pp. 23897-23915.

Yu M.-M., Chen P.-C. (2011), "Measuring air routes performance using a fractional network data envelopment analysis model", Central European Journal of Operations Research, Vol. 19 No. 1, pp. 81-98. 
Zhu W., Yang X., Preston J. (2016), "Efficiency measurement of bus routes and exogenous operating environment effects on efficiency", Transportation Planning and Technology, Vol. 39 No. 5, pp. 464-483. 